\title{
Transdisciplinary Knowledge Integration within Large Research Programs
}

Research is increasingly organized as large programs. A growing number of such programs produce a synthesis

that links and relates scientific results of individual projects and integrates them into an overarching context.

The synthesis thus creates an added value that goes beyond individual project results. Which methods and procedures are used to generate that added value?

This paper presents methods and procedures of transdisciplinary knowledge

integration that were applied within four thematic syntheses of the Swiss

National Research Programme on Sustainable Water Management (NRP 61).

Sabine Hoffmann

Transdisciplinary Knowledge Integration within Large Research Programs | GAIA 25/3 (2016): 201-203

Keywords: knowledge integration, methods, procedures, research programs, sustainable water management, synthesis, transdisciplinary research

\section{Knowledge Integration - a Key Challenge}

Knowledge integration is widely regarded as a key challenge of inter- and transdisciplinary research (Bammer 2005, Bergmann et al. 2005, Truffer 2007, Klein 2008, McDonald et al. 2009, Jahn et al. 2012). In a transdisciplinary context, it means the interrelation of different bodies of knowledge from science and practice (e.g., transcending disciplinary boundaries and bridging theory and practice) to create a more comprehensive understanding of a societal problem (Jahn 2008, Pohl and Hirsch Hadorn 2008). It also implies both the generation of practice-oriented solutions and their diffusion among the target audience (Bergmann et al. 2005, Defila et al. 2006). Transdisciplinary knowledge integration is thus expected to contribute to societal problem solving (Truffer 2007, Klein 2012).

This paper explores transdisciplinary knowledge integration within the Swiss National Research Programme on Sustainable Water Management (NRP 61). Funded by the Swiss National Science Foundation (SNSF), the program aimed to develop scientific foundations, methods and strategies for the sustainable management of Switzerland's water resources (SNSF 2010). It involved 16 inter- and transdisciplinary research projects carried out between 2010 and 2013 and four thematic synthesis projects generating targeted synthesis reports (TS). Published at the end of the program, the reports addressed four topics: water resources in Switzerland (TS 1) (Björnsen Gurung and Stähli 2014), management of water resources under growing user demands (TS 2) (Lanz et al. 2014), sustainable water and wastewater management (TS 3) (Hoffmann et al. 2014), and sustainable water governance (TS 4) (Schmid et al. 2014). In addition, the program included an associated research on transdisciplinary knowledge integration within the four synthesis projects, which was conducted by the author.
The research aimed at exploring methods and procedures used by the four TS to link and relate scientific results of individual research projects and integrate them into an overarching context (SNSF 2012).

Summarizing the results of the associated research, the paper 1. illustrates transdisciplinary knowledge integration within NRP 61, using the example of TS 3, and 2. compares knowledge integration across the four TS, applying an analytical framework that connects two aspects of integration that have previously been studied, that is, procedures by which knowledge integration is organized within a team (Rossini and Porter 1979, Pohl and Hirsch Hadorn 2007) and methods by which knowledge is linked and related to each other (Bergmann et al. 2012; for details on the framework, see Hoffmann et al. forthcoming).

\section{Knowledge Integration Exemplified}

Transdisciplinary knowledge integration within TS 3 was led by a core team composed of three NRP 61 researchers, including the author. It aimed at generating three different types of knowledge relevant for urban water management in Switzerland (figure 1, p. 202): 1. systems knowledge about current and future challenges of urban water management and the causal links that underlie

Contact: Dr. Sabine Hoffmann | Swiss Federal Institute of Aquatic Science and Technology (Eawag) | Überlandstr. 133 | 8600 Dübendorf | Switzerland | Tel.: +41587656818 | E-Mail: sabine.hoffmann@eawag.ch

(c) 2016 S. Hoffmann; licensee oekom verlag. This is an Open Access article distributed under the terms of the Creative Commons Attribution License (http://creativecommons.org/licenses/by/3.0), which permits unrestricted use, distribution and reproduction in any medium, provided the original work is properly cited. 


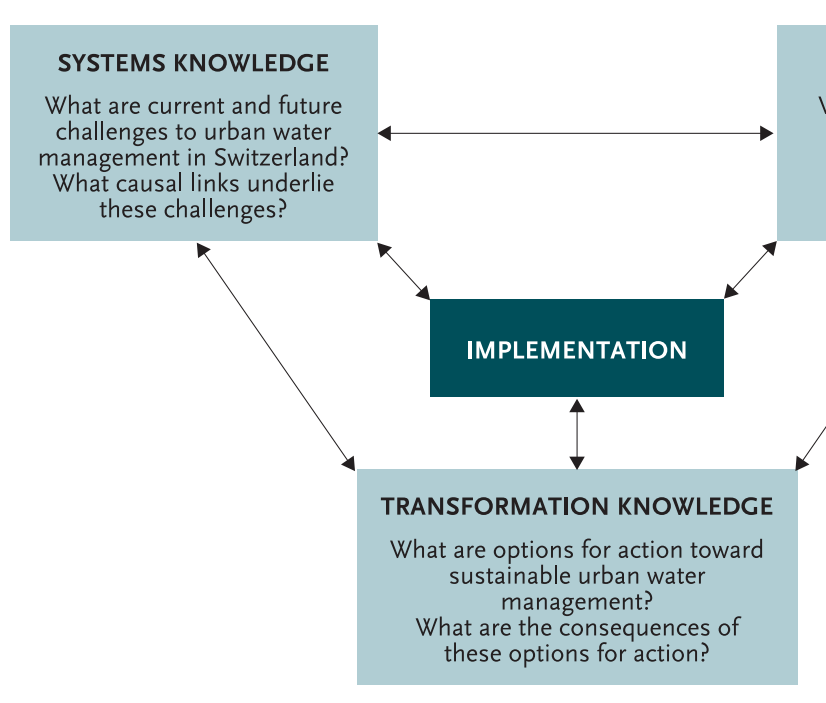

these challenges, 2. target knowledge about social, ecological, and economic targets of sustainable urban water management, 3. transformation knowledge about options for action toward sustainable urban water management and their consequences with respect to target achievement. In general, these three types of knowledge are interdependent (Pohl and Hirsch Hadorn 2007): new integrated insights on one type of knowledge require reconsidering the other types of knowledge as parts of the assumptions underlying them might have changed (Wuelser et al. 2012, p. 89).

To answer the research questions (figure 1 ) with respect to each type of knowledge, the core team combined scientific results of seven individual research projects and engaged in consultation and collaboration with NRP 61 researchers and practitioners. It used key elements of system analysis including drivers, pressures, state, impact and responses (DPSIR) in order to identify, prioritize and analyze current and future challenges to urban water management, explore the underlying causal links, and devise options for action. It also applied key elements of multi-criteria decision analysis (MCDA) to define targets of sustainable urban water man-
TARGET KNOWLEDGE

What are social, ecological and economic targets water management in Switzerland? of sustainable urban
FIGURE 1: Transdisciplinary knowledge integration: research questions to systems, target the synthesis project on sustainable urban water management (Hoffmann et al. 2014, based on CASS and ProClim 1997). and transformation knowledge addressed within

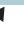

ter and wastewater companies, stakeholder networks and trade associations), thus creating an added value that went above and beyond the results of the individual projects.

The final results of the knowledge integration show that many options for action related to "water infrastructures" and "water resources" contribute significantly to the sustainability targets "intergenerational equity", "good water supply", "good water protection”, „safe wastewater disposal" and "efficient resource use", while only some are conducive to "high social acceptance" and "low costs". Many options related to "knowledge" - for example, improving knowledge integration across different decision levels (municipal, cantonal, federal) and sectors (water supply, wastewater treatment), or fostering knowledge exchange between science and practice - are robust "no-regret" options (Hoffmann et al. 2014). The integrated results suggest that the agreement on overarching targets among all actors involved in urban water infrastructure planning processes is a critical first step toward the sustainable management of urban water infrastructure in Switzerland. The integrated results provided by TS 3 constitute an important basis for supporting these planning processes.

\section{Comparing Ways of Knowledge Integration}

The comparison of methods and procedures of transdisciplinary knowledge integration within the four TS is based on analyses of written documents (e.g., proposals, reports, articles, and presentations of all TS), semi-structured interviews with core team members of all TS, and participant observations in NRP 61 program meetings (Hoffmann et al. forthcoming). All in all, the four TS

\section{The ex-post self-evaluation of the overall synthesis process revealed the need for structuring transdisciplinary knowledge integration from the outset, by defining the object and purpose of knowledge integration, identifying common objectives and questions, and developing a joint vision.}

agement and assess the potential consequences of different options with regard to target achievement. Combining key elements of DPSIR and MCDA enabled the core team to link systems and target knowledge provided by different individual projects in a coherent and consistent way. It also enabled the team to generate new transformation knowledge tailored to the specific needs of the target audience (e.g., federal, cantonal and municipal authorities, wa- applied a variety of integration methods, including the formulation of research questions and hypotheses (TS 1, 2, 3, 4), the definition of concepts and theoretical frameworks (TS 1), the design of assessment procedures (TS 3, 4), the development and application of models (TS 1,2,3), and the creation of boundary objects (TS 1,2) (cf. Bergmann et al. 2012). TS 3 was unique in developing an integrative method in order to relate different types of knowl- 
edge. It relied more on procedures by which transdisciplinary knowledge integration was carried out by a group of experts from science and practice than on integration by a leader (cf. Rossini and Porter 1979) used predominantly by other TS.

The overlapping timeframes of the four TS and the associated research enabled a process of mutual learning among core team members of all TS by jointly reflecting on strengths and weaknesses of different methods and procedures of knowledge integration. The reflection triggered some adaptations in the ongoing synthesis processes and stimulated the ex-post self-evaluation of the overall synthesis process (Hoffmann et al. submitted). The selfevaluation revealed the need for structuring transdisciplinary knowledge integration from the outset, by 1 . defining the object and purpose of knowledge integration, 2. identifying common objectives and questions, 3. developing a joint vision for knowledge integration (Defila et al. 2006, Wiek 2007, Lang et al. 2012). The latter serves as a basis for defining different integration steps and identifying for each step the methods and procedures to be applied and the actors to be involved in the process (Krütli et al. 2010, Lang et al. 2012, Hoffmann et al. forthcoming). It also emphasized the need for further research on roles and responsibilities of researchers (and practitioners) leading transdisciplinary knowledge integration within large research programs (Hoffmann et al. forthcoming).

\section{References}

Bammer, G. 2005. Integration and implementation sciences: Building a new specialization. Ecology and Society 10/2: Art. 6.

Bergmann, M., T. Jahn, T. Knobloch, W. Krohn, C. Pohl, E. Schramm. 2012. Methods for transdisciplinary research: A primer for practice. Frankfurt am Main: Campus.

Bergmann, M. et al. 2005. Quality criteria of transdisciplinary research: A guide for the formative evaluation of research projects. Studientexte des Instituts für sozial-ökologische Forschung. Frankfurt am Main: Institute for Social-Ecological Research (ISOE).

Björnsen Gurung, A., M. Stähli. 2014. Wasserressourcen der Schweiz: Dargebot und Nutzung - heute und morgen. Thematische Synthese $1 \mathrm{im}$ Rahmen des Nationalen Forschungsprogramms NFP 61 „Nachhaltige Wassernutzung“. Bern. www.nfp61.ch/SiteCollectionDocuments/nfp61_thematische_ synthese_1_d.pdf (accessed July 27, 2016).

CASS (Conference of the Swiss Scientific Academies), ProClim (Forum for Climate and Global Change Swiss Academy of Sciences). 1997. Research on sustainability and global change - Visions in science policy by Swiss researchers. Bern: ProClim.

Defila, R., A. Di Giulio, M. Scheuermann. 2006. Forschungsverbundmanagement. Handbuch für die Gestaltung inter- und transdisziplinärer Projekte. Zürich: vdf Hochschulverlag.

Hoffmann, S., D. Hunkeler, M. Maurer. 2014. Nachhaltige Wasserversorgung und Abwasserentsorgung in der Schweiz: Herausforderungen und Handlungsoptionen. Thematische Synthese 3 im Rahmen des Nationalen Forschungsprogramms NFP 61 „Nachhaltige Wassernutzung“. Bern. www.nfp61.ch/ SiteCollectionDocuments/nfp61_thematische_synthese_3_d.pdf (accessed July 27, 2016).

Hoffmann, S., C. Pohl, J. Hering. Forthcoming. Methods and procedures of transdisciplinary knowledge integration: Empirical insights from four thematic synthesis processes. Ecology and Society.

Hoffmann, S., C. Pohl, J. Hering. Submitted. Exploring transdisciplinary integration within a large research program: empirical lessons from four thematic synthesis processes. Research Policy.
Jahn, T. 2008. Transdisziplinarität in der Forschungspraxis. In: Transdisziplinäre Forschung. Integrative Forschungsprozesse verstehen und bewerten. Edited by M. Bergmann, E. Schramm. Frankfurt am Main: Campus. 21-38.

Jahn, T., M. Bergmann, F. Keil. 2012. Transdisciplinarity: Between mainstreaming and marginalization. Ecological Economics 79: 1-10.

Klein, J. T. 2008. Evaluation of interdisciplinary and transdisciplinary research: A literature review. American Journal of Preventive Medicine 35/2: S116-S123.

Klein, J. T. 2012. Research integration: A comparative knowledge base. In: Case studies in interdisciplinary research. Edited by A. F. Repko, W. H. Newell, R. Szostak. Thousand Oaks, CA: Sage. 283-298.

Krütli, P., M. Stauffacher, T. Flüeler, R. W. Scholz. 2010. Functional-dynamic public participation in technological decision-making: Site selection processes of nuclear waste repositories. Journal of Risk Research 13/7: $861-875$.

Lang, D. J. et al. 2012. Transdisciplinary research in sustainability science: Practice, principles, and challenges. Sustainability Science 7/Supplement 1: $25-43$.

Lanz, K., E. Rahn, R. Siber, C. Stamm. 2014. Bewirtschaftung der Wasserressourcen unter steigendem Nutzungsdruck. Thematische Synthese 2 im Rahmen des Nationalen Forschungsprogramms NFP 61 „Nachhaltige Wassernutzung“. Bern. www.nfp61.ch/SiteCollectionDocuments/nfp61_thematische_synthese_2_d. pdf (accessed July 27, 2016).

McDonald, D., G. Bammer, P. Deane. 2009. Research integration using dialogue methods. Canberra: ANU Press.

Pohl, C., G. Hirsch Hadorn. 2007. Principles for designing transdisciplinary research. Munich: oekom.

Pohl, C., G. Hirsch Hadorn. 2008. Methodological challenges of transdisciplinary research. Natures Sciences Sociétés 16/2:111-121.

Rossini, F.A., A. L. Porter. 1979. Frameworks for integrating interdisciplinary research. Research Policy 8/1: 70-79.

Schmid, F., F. Walter, F. Schneider, S. Rist. 2014. Nachhaltige Wassergouvernanz: Herausforderungen und Wege in die Zukunft.. Thematische Synthese 4 im Rahmen des Nationalen Forschungsprogramms NFP 61 „Nachhaltige Wassernutzung“. Bern www.snf.ch/SiteCollectionDocuments/medien mitteilungen/mm_141106_nfp61_thematische_synthese_4_d.pdf (accessed July 27, 2016).

SNSF (Swiss National Science Foundation). 2010. Sustainable water management. Portrait of the National Research Programme NRP 61. Bern: SNSF.

SNSF. 2012. Final products Q programme syntheses in National Research Programmes (NRPs). Bern: SNSF.

Truffer, B. 2007. Wissensintegration in transdisziplinären Projekten. Flexibles Rollenverständnis als Schlüsselkompetenz für das Schnittstellenmanagement. GAIA 16/1: 41-45.

Wiek, A. 2007. Challenges of transdisciplinary research as interactive knowledge generation: Experiences from transdisciplinary case study research. GAIA 16/1: 52-57.

Wuelser, G., C. Pohl, G. Hirsch Hadorn. 2012. Structuring complexity for tailoring research contributions to sustainable development: A framework. Sustainability Science 7/1: 81-93.

Submitted May 30, 2016; revised version accepted July 12, 2016.

Sabine Hoffmann

Born 1971 in Kassel, Germany. 2010 PhD in development studies. 2010 to 2014 coordinator and researcher within the Swiss National Research Programme on Sustainable Water Management (NRP 61). Since 2015 group leader Transdisciplinary Research in the Environmental Social

Sciences (ESS) Department at the Swiss Federal Institute of Aquatic Science and Technology (Eawag), Dübendorf. Research interests: management of transdisciplinary research, transdisciplinary knowledge integration. 